\title{
Decision-Making Processes Among Potential Dropouts in Vocational Education and Training and Adult Learning
}

\author{
Vibe Aarkrog*, Bjarne Wahlgren, Christian Hougaard Larsen, \\ Kristina Mariager-Anderson, and Susanne Gottlieb \\ DPU/ Aarhus Universitet, Tuborgvej 164, 2400 København, Denmark
}

Received: 22.12.2017; Accepted: 22.05.2018; Published: 30.08.2018

\begin{abstract}
Context: Aiming at gaining knowledge about students' thoughts and actions in deciding to stay in or drop out of an educational programme, an empirical study was conducted on dropout among 18-24-year-old students in VET and basic general adult learning.
\end{abstract}

Approach: In order to pursue this aim, the study combined two sets of data: weekly student surveys and interviews with these same students. While the surveys provide a weekly snapshot of the students' thoughts regarding the probability of them continuing in the programme, their satisfaction with the educational programme as a whole, the specific lessons they attend, and the atmosphere at the school, the interviews contribute with detailed descriptions of the students' thoughts on the same matters.

Findings: Based on the students' answers over an eight-week period, it was possible to trace a graph illustrating changes in the students' attitudes. These graphs can be placed within four categories of development: the stable, the positive, the unstable, and the negative. The latter can furthermore be differentiated as reflecting a stable decline, a fluctuating decline, or a sudden decline. In the interviews, the aim was to elicit the individual students' thoughts and actions at the points when their graphs took a turn.

Conclusions: The findings show that the students' thoughts and actions concern matters both inside and outside the school. Furthermore, seemingly trivial matters in the

${ }^{*}$ Corresponding author: viaa@edu.au.dk

ISSN: 2197-8646

http://www.ijrvet.net 
students' lives are shown to have a potentially decisive influence on the students' thoughts about staying in or dropping out of a programme. These findings confirm the importance of focusing on students' decision-making processes in research on dropout. However, further research is needed to increase understanding of processes leading to decisions to drop out of education, including the qualification of methods to capture these processes.

Keywords: VET, Vocational Education and Training, Dropout, Decision-Making Process, Teetering, Young Adults, Adult Learning

Paper Type: Research Article

\section{Introduction}

Dropout among young adults (18-24 years old) is high: a report from CEDEFOP shows that dropout has been prioritized in EU policy since the adoption of the Lisbon strategy in 2000, with the current aim being to reduce dropout for this group to below $10 \%$ by 2020 (Cedefop, 2016). In Denmark, 20\% of each youth cohort has not completed an upper secondary or VET qualification seven years after completing lower secondary education (Ekspertgruppen, 2017). These young adults constitute a particularly vulnerable group. They often struggle with traditional classroom-based learning, have difficulties in book learning; they have social and psychological problems and they have a history of dropout. This group is central in an ongoing research project on dropout among Danish 18-24-yearold students in vocational education and training (VET) and general adult education: "To stay on track. New perspectives and sustainable solutions to dropout among young adults." The article is part of this three-year project, conducted 2017-2019.

As a very widely researched issue, one may ask why there is a need for yet another research project about dropout. However, previous research has mostly studied students' reasons for dropping out, resulting in a complex tapestry of the motives for dropout. Meanwhile, there is little research concerning students' decision-making processes in relation to dropout. What do the students think and do in relation to events, leading to dropping out? The aim of the research project is to improve strategies for preventing dropout by gaining knowledge about students' thoughts and actions related to decisions to stay in or drop out of an educational programme.

In Denmark, VET for young adults include a basic 20 weeks course followed by a main course, in which the students alternate between school-based education and training and workplace-based training. Depending on the qualification level of the program, the main course has a duration of 1 to 3 years. Many of the students in this age group have to complete basic general qualifications in maths and Danish in order to enrol in VET.

The educational programmes included in the study are either basic vocational courses, situated in vocational colleges, or general, situated in adult education centres. These basic general education programmes qualify young adults for enrolment in a VET programme. Thus, students in the basic general programs are often the same kind of students one will meet in VET. The study does not include dropout in relation to workplace-based training. 


\section{Review of Literature}

As the study deals with school-based education, the review focuses on dropout in relation to school-based education. Most of the research on dropout, including Danish research on dropout in VET (Jørgensen, 2011) has focused on the factors that contribute to an increase in the probability of young people leaving school before time. Lamb (2011) presents a conceptual model of the factors affecting dropout and completion based on such research, summarizing the research in four dimensions: 1) Individual attributes, which include the student's personal settings and background characteristics, such as gender, age, race, financial position, self-esteem, self-efficacy, and health; 2) Institutional context, which includes family and other social networks, school structure and organization, policy settings, class size and composition, student-teacher ratio, and teaching styles, attributes, and resources; 3) Dispositions, which include students' academic engagement, achievements, and abilities; 4) Outcomes, which include attainment, dropout and completion rates, and young people's decisions to complete or drop out of education (Lamb, 2011; Cournoyer \& Deschenaux, 2017).

As noted by Lamb (2011), the research literature shows that dropout might be the result of complicated, interrelated, and simultaneous processes in which the various risk factors and dimensions affect each other. As described by Ferguson et al. (2005), the dropout process should be viewed as a non-linear, inter-relational, and fragmented disengagement process, characterized by paradoxes and a multiplicity of factors.

The research reveals a tendency to study dropout as the cumulative result of multiple risk factors that can be identified rather early in a person's life. As suggested by Alexander et al. (1997) and Rumberger and Rotermund (2012), dropout must be analysed as a long-term process of disengagement rather than as a binary incident or a monumental decision. Supporting the life course and long-term perspective on dropout, the research literature further proposes that dropout and the personal decision to leave school should be seen as a reaction to a longer period of academic alienation (Fine 1991; Fine and Rosenberg 1983; Brown and Rodriquez 2009) or as the culmination of a prolonged withdrawal process (Finn, 1989; Rumberger, 2004).

Hodgson (2007) proposes that dropping out of school be thought of as a longer institutional and relational process in which the school and the student co-construct the decision to leave school. He argues that dropout is unfolded by a set of experiences, interactions, and processes between the student and educators, peers, and the logics of education, leading to growing despair, resignation, hopelessness, and, in some cases, more or less tacit invitations by the school to leave. A study by Lee and Burkham (2003) shows that not only the students but also the school influence the students' cumulative process of disengagement. Archambault et al. (2009) likewise apply a processual perspective on dropout, revealing that the dropout process may begin at an earlier point than might be expected, indicating that student disengagement first be expressed psychologically rather than behaviourally. Later, the negative cognitive state evolves, and disengagement is manifested in more observable actions and behaviours. The study further shows that a decrease in motivation and school interest leads to school alienation and misbehaviour. 
Based on a longitudinal study of 143 children, and on Evans and DiBenedetto's idea of a "snowballing effect", a study by Jimerson et al. (2000) shows that the decision to leave school at the age of 19 is affected by and associated with early home environment, socioeconomic status, behaviour, academic achievement, and parent involvement. The study also shows that early school experiences may affect self-esteem, establishing negative behaviours and relationships with teachers and peers "that further propel the individuals along a pathway towards dropping out" (Jimerson et al., 2000, p. 543).

The existing research on dropout thus documents an interrelation between individual and institutional factors. However, knowledge that is more specific and a more complex understanding are needed in order to shed light on the simultaneous interaction between the different risk factors and the students' individual thoughts and actions in a specific dropout process. To be able to describe and examine this process, the study presented in this article revisits the notion of teetering introduced by Lessard et al. (2007).

The notion of teetering has been chosen to describe how dropouts are often off balance during what Lessard et al. conceptualize as their educational journeys. Based on 80 interviews with high school dropouts, Lessard et al. argue that there seem to be forces at work both keeping the students in school and pulling them away: "these forces contributed to the tug of war taking place between in and out-of-school contexts" (Lessard et al., 2007, p. 32). Teetering represents the processual category between "setting the stage", which includes elements that shape the educational journey (personal history, family turmoil), and "ending the journey", which denotes the actual moment when the student leaves school, either gradually fading out or abruptly dropping out. Based on the 80 narratives, Lessard et al. categorize four strategies, i.e. patterns of thought and behaviour that the students use, more or less consciously, for "prolonging"/staying in school.

The notion of teetering captures how different patterns of thought and behaviour interact during a particular process. By focusing on the processes that lead to dropout instead of on the exact moment of dropping out, the notion of teetering illustrates the psychosocial complexity, thoughts, actions, and balancing acts that characterize this process. In order to gain knowledge about the students' thoughts and actions in deciding whether to stay in or drop out of an educational programme, this study combines the processual view on dropout with the notion of teetering.

The research in the field of decision-making has mainly focused on career decisionmaking, usually by categorizing an individual's "type" or "style" and its effect on a career decision-making process (Harren, 1979; Phillips \& Pazienza, 1988; Blustein, 1987; Phillips et al., 1984). As noted by Mau (2000), research findings in the field of careerdecision making are inconsistent, indicating that the effectiveness of what is often assumed to be the most effective decision-making style, the rational, may be situational and dependent on personal factors and characteristics of decisional tasks during the process (Mau, 2000). There is a need for research on the decision-making processes leading to either educational dropout or retention that focuses on the students' thoughts and actions during periods when they are in doubt as to whether they should continue or not with a particular educational programme. 
The process of decision-making is important in understanding and describing the student's thoughts and actions in a process leading to staying in or dropping out of an educational programme. As described by Hunt et al. (1989), human decisions are often more judgmental than mechanical, i.e. more unstructured cognitive processes than rational processes. Inspired by Hunt et al., it is furthermore possible to characterize decision-making processes as cognitive processes by which an individual develops models of "reality" to develop, create, and organize action.

Harren defines decision-making style as an individuals characteristic mode of receiving and responding to certain tasks 1 during the decision-making process and, in general, the way a person goes about making decisions (Harren, 1979). Harren identified a typology of three styles, which can be placed on a continuum. This illustrates the degree to which an individual takes responsibility for the process and to which this individual uses logic (the more rational), emotions and feelings (the more intuitive), or expectations of authorities and peers (the more dependent) as the primary approach in thoughts and actions during the decision-making process (Harren, 1979).

To transcend the focus on a single, rigorous approach to decision-making styles, Gati et al. (2010) propose a multidimensional model for characterizing decision-making, referring to decision-making profiles instead of styles, indicating that decision-making is a "complex, multidimensional construct rather than a single dominant trait" (Gati et al., 2010, p. 278).

In the project, "To stay on track. New perspectives and sustainable solutions to dropout among young adults." the focus is solely on the students' decision-making processes and not so much on the result of these processes. Inspired by the above mentioned explorations of decision-making processes, the aim of this article is to present the preliminary findings from the project, regarding the students' thoughts, feelings, and actions during periods of increased risk of dropping out. That is, periods during young adults' education when they become more uncertain of their motivation to continue within a particular programme.

With the aim of obtaining knowledge about students' thoughts and actions during periods of heightened risk in the educational programme, the article addresses the following four research questions:

1. How do students' motivation to continue in an educational programme develop over time?

2. What leads students to change their minds about staying or dropping out?

3. What do students think, feel, and do during periods in which they alter their perceptions of staying or dropping out of a programme?

4. How do students typically decide whether they want to continue their current educational programme?

\footnotetext{
${ }^{1}$ Inspired by Harren's (1979) definition of "tasks", examples of "tasks" in a dropout or retention context could be engaging in social activities', making friends (getting a boyfriend/girlfriend)', and getting feedback'. The tasks include those elements and situations that concern the particular decision-making process: developing autonomy, interpersonal maturity, and a sense of purpose.
} 


\section{Method}

Data consists of surveys and interviews conducted with 31 students during the autumn of 2017.

\subsection{Student Surveys}

The purpose of the student-surveys was to study how their motivation to continue in the specific educational programme develops over time (research question 1). Assuming that their satisfaction with the programme in general, the lessons, and the atmosphere at the school has an impact on their motivation to continue, a multidimensional construct including the following four questions was used:

1. How satisfied are you with this programme?

2. How satisfied are you with the lessons (the teaching)?

3. How satisfied are you with the atmosphere at the school?

4. How strong is your motivation to continue in this programme?

Every week during the autumn term, a total of 15 weeks, the students were asked to answer the four questions according to a Likert scale ranging from 1-7 ( $1=$ the lowest and $7=$ the highest). Repeating the survey over the whole term enabled an emerging pattern of developments in the students' attitudes.

At the time of the initial survey, the 31 interviewed students were enrolled in programmes at 14 schools (six vocational colleges and eight adult general education centres). The 31 students were selected by the schools, the criterion being that the schools - based on interviews conducted with students at the beginning of the term - believed these students to be at risk of dropping out. The reason for focusing on potential dropouts was that the project aims at providing a varied picture of the group of students at risk of dropping out.

This article presents the results of an analysis of graphs plotting students' responses to the surveys across an eight-week period. Almost all students had answered the survey every week, with only a few skipping a week due to illness. Based on their responses, four graphs were plotted for each student reflecting the student's answers to each of the four questions above.

The graphs were analysed in order to categorize different types of development. The analysis focused on the fourth research question, "How strong is your motivation to continue in this programme", paying attention to both the degree of fluctuation (between 1 and 7 on the Likert scale) and the direction of the graphs (ascending or descending).

The graphs showing the students' answers to the remaining questions 1-3 were included in the analysis in two ways. Firstly, the coherence was analysed between the students' graphs showing their answers to question 4 and their answers to questions 1-3. Secondly, the interviews with the students used their answers to all four questions as a jumping-off point. 


\subsection{Student Interviews}

The purpose of the interviews with the 31 students was to elicit the students' narratives about their thoughts, feelings, and actions at the points when the graphs changed.

The interviews were semi-structured and took their point of departure in the individual student's graphs depicting the student's answers to the four questions in the eightweek-period. Looking at the development of student's graphs, the researcher and the student talked about the students' thoughts, feelings, and actions, following two lines of questioning reflecting the research questions above:

1. What happened at the time when you answered differently, i.e. when the graph or graphs changed? This included the students' explanations of the graphs showing answers to questions 1-3 in the survey, as well as referencing to other specific events at school or events occurring outside school, e.g. mental health or personal problems. (Research question 2 above).

2. What did you think, feel and do at the time when the graph changed? (research question 3 above).

Each interview was recorded, had a duration of $1 / 2-3 / 4$ of an hour and transcribed.

\section{Results}

The results are based on an analysis of the students' answers to question no. 4: "How strong is your motivation to continue in this programme?"; an analysis of the coherence between the students' answers to question 4 and questions 1-3; and finally an analysis of the students' narratives about the events, thoughts, and actions related to the graphs showing an unstable or negative developmental tendency (see below).

\subsection{Four Categories of Development}

In relation to research question 1 and based on an analysis of question 4: "How strong is your motivation to continue in this programme?" four categories of development have been defined:

1. The stable development (11 students)

2. The positive development (4 students)

3. The unstable development (4 students)

4. The negative development (12 students)

The Stable Development is illustrated by graphs of 11 students. These have been defined as showing no development when comparing the initial position with the final position, values fluctuating slightly around the mean value. Graphs of half of these students (6) are positioned at a relatively high level during the whole period, oscillating between 
5 and 7 on the scale. These students want to continue their current programme no matter what. Graphs of the remaining students (5) are positioned in the middle of the scale, oscillating between 2 and 5 on the 7 point scale.

The positive development is illustrated by the graphs of four student. Two students move from being 'certain' to 'very certain' that they will continue in their current programme. The other two move from being 'not certain' to reasonably certain'.

The unstable development includes the graphs of four students. As was the case for the graphs illustrating a stable development, the analysis of these four graphs shows no systematic change. The graphs show considerable fluctuations, with values oscillating between 1 and 7; however, values at the beginning and end of the period remain the same.

The negative development is illustrated by the graphs of 12 students. Most of these students (10) initially state a high probability of continuing in their current programme. More than half of the students (7) become increasingly negative, eventually at the end of the eight-week-period stating their likelihood of continuing in the programme at level 3 or 4 . Three students move from being very certain (6-7) to very uncertain (1) that they will continue. Two students, who initially assessed their probability of continuing in their current programme at levels 4 or 5 , become less certain during the survey period.

Summing up, for half of the 31 students their ratings during the survey period do not reflect a consistent pattern of change. More than one third of the students (12 out of 31 students) go through a negative development', becoming less certain that they will continue in their current programme. Finally, a few of the students (4) seem to undergo a positive development, becoming more certain that they will continue in their current programme.

\subsection{Students' Motivation to Continue in the Programme and their Satisfaction with Programmes, Lessons and Atmosphere}

In relation to research question 2 and 3 above, the data show coherence between the students' responses regarding how motivated they are for continuing in their current programme (question 4) and their satisfaction with the programme, lessons, and the atmosphere at the school (questions 1-3). The graphs plotting responses to questions 1-3 for students whose responses to question 4 show a stable' or a positive' development may show certain fluctuations. For example, a student expresses dissatisfaction with the lessons or with the atmosphere at the school in one of the weekly surveys, perhaps due to a particular negative experience. However, in most cases these fluctuations do not affect the students' motivation to continue their studies: the graph for question 4 remains stable. However, examples of the opposite can also be found; i.e. motivation to continue in the programme' follows the same graph as, for example, satisfaction with the atmosphere at the school'.

With regard to the four students with an unstable development', the graphs for each of the four questions oscillate considerably, but these changes are not necessarily consistent across the four graphs. One week the student can express dissatisfaction with the lessons, another week with the atmosphere at the school. In relation to research question 2 above, 
the results show that it is difficult to pinpoint what makes the students' graphs oscillate.

For the 12 students categorized as following a negative development', the graphs plotting their answers to questions 1-3 generally correlate with the graph showing the answers to question 4 , indicating that, whereas the students following a stable development' are relatively unaffected by events at school, the students with unstable' or negative' developments are sensitive towards such events. The students seem to feel that everything develops in a negative direction. However, among the students in this category one also finds examples showing that their satisfaction with the atmosphere at the school or with the lessons does not directly influence their motivation to continue in their current programme. It is therefore not possible to determine which of the three factors has the greatest impact on the students' motivation to continue their studies.

Answers to questions 1-3 show that responses to the three questions follow a similar tendency. However, examples of the opposite tendency can also be found, with students expressing significantly different degrees of satisfaction regarding the three factors.

Finally, the analysis of the graphs shows that the students perceive the same situations differently. In the data, one can find examples of both major and minor variations in the individual student's weekly survey responses. It can be argued that this reflects differing degrees of sensitivity to changes at school or in the lessons. When comparing responses from students in the same class at the same school, the graphs differ substantially. As such, students can perceive the same class and the same teaching very differently.

\subsection{The Unstable and Negative Graphs Exemplified from Student Interviews}

Among the 31 student interviews, the article focuses on the students seemingly most likely to drop out, i.e. the students belonging to the categories the unstable development' (4 students) and the negative development' (12 students).

In the following presentation of the results from the student interviews, we compare the graphs to the students' narratives regarding what happened at the time when the graph changed and what they thought, felt and did at that time.

\subsection{The Unstable Development Exemplified}

The students in this category oscillate significantly over time in their answers to all four questions. They typically have problems both inside and outside school. School is to some extent perceived as a refuge when the external problems dominate. This can somewhat explain why the students stay in the programme. 


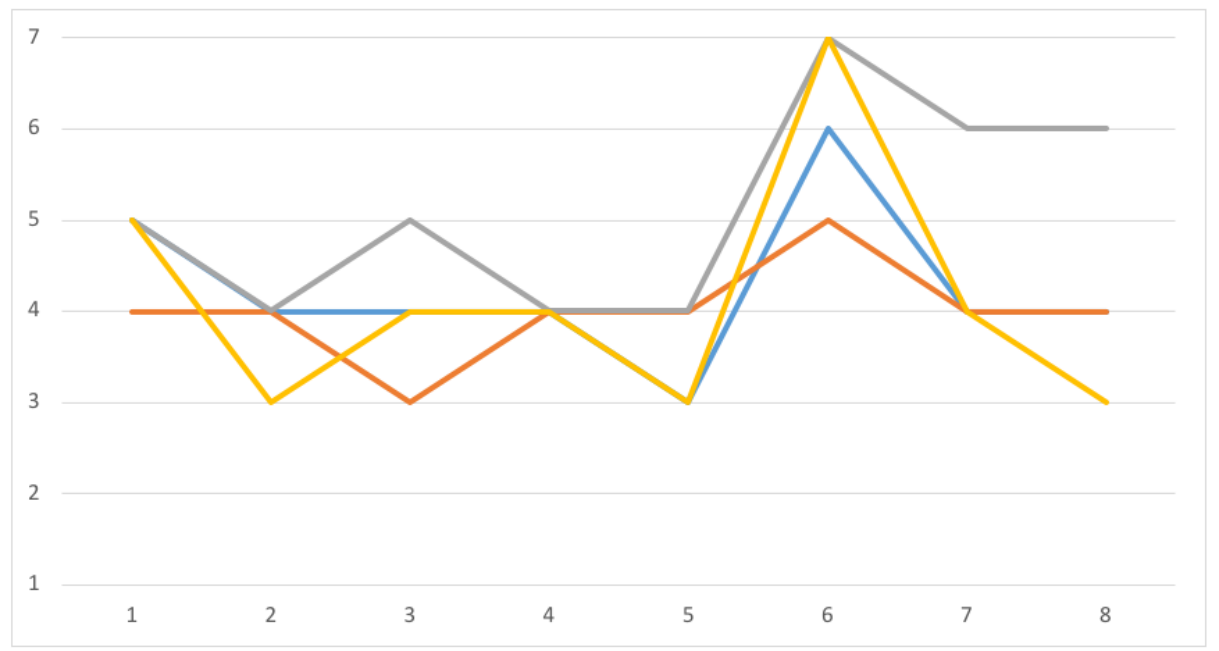

Figure 1: Mark, male student. Blue: satisfaction with the programme; orange: satisfaction with the lessons, grey: satisfaction with the atmosphere; yellow: motivation to continue in the programme.

The strongly oscillating graph characterizes students who are highly sensitive towards quite small changes, such as Mark, 22 years old (figure 1), who is studying general subjects in order to enrol in an as yet undefined VET programme. Mark does not like maths lessons: "We have maths on Monday and I answered the survey on a Monday, so I was just in a bad mood". Regarding his thoughts and actions in relation to the oscillating graph, he says: "I have good and bad days, often related to whether I can keep up academically; in particular with maths, which stresses me and pressures me emotionally. I might also have had a bad morning, or private problems, which depresses me; sometimes it is just trivial things. However, then I start to bunk off; I don't bother; I feel I'm wasting my time. I think that this doesn't make sense to me and I find something else to do. I feel blank."

The social atmosphere at school is crucial for Mark's satisfaction with the programme and his motivation for going to school and continuing in the programme, as can be seen in the sixth week, where the grey, the blue and the yellow graphs take the same upward direction. "I always think twice before just dropping out; I really like to be with my classmates." However, Mark is also influenced by other issues referring to his personality: "I want to be in control of my own life, and I need to obtain the qualifications". Mark is satisfied with his classmates, the teachers, and the guidance counsellors, and he takes action by discussing his situation with a guidance counsellor. Subjects like maths may pull him in the direction of dropping out; the relation to the classmates and the guidance counsellor pulls him in the opposite direction to stay in the programme. The teetering process for this student shows, on the one hand, that he is easily affected by trivial things' and that he is at risk of dropping out. On the other hand, he knows that he is in charge of his own life and that he is responsible for completing the programme. Mark 
completes the programme.

Another student in this category of four students is Jens, who is training for a qualification in a business programme. He wants to enrol in a programme for hairdressers, but needs a commercial qualification to establish and run his own salon. Like Mark, Jens encounters problems in his private life, uses school as a refuge, and has difficulties concentrating on the academic work because he thinks too much about his private problems and considers dropping out. However, he is also aware that he needs to complete the programme and that doing so is his own responsibility. Jens completes the programme.

\subsection{The Negative Development Exemplified}

The category negative development' includes 12 students whose motivation to continue their studies shows a negative development. The category can be divided into three subcategories: stable decline', fluctuating decline', or sudden decline'. Below are examples of these categories.

Students with a stable decline generally struggle with problems both inside and outside school and suffer from physical or, most often, psychological problems. At the beginning of the programme, they are optimistic that they will continue. However, after a couple of weeks, the graph starts to show a decline.

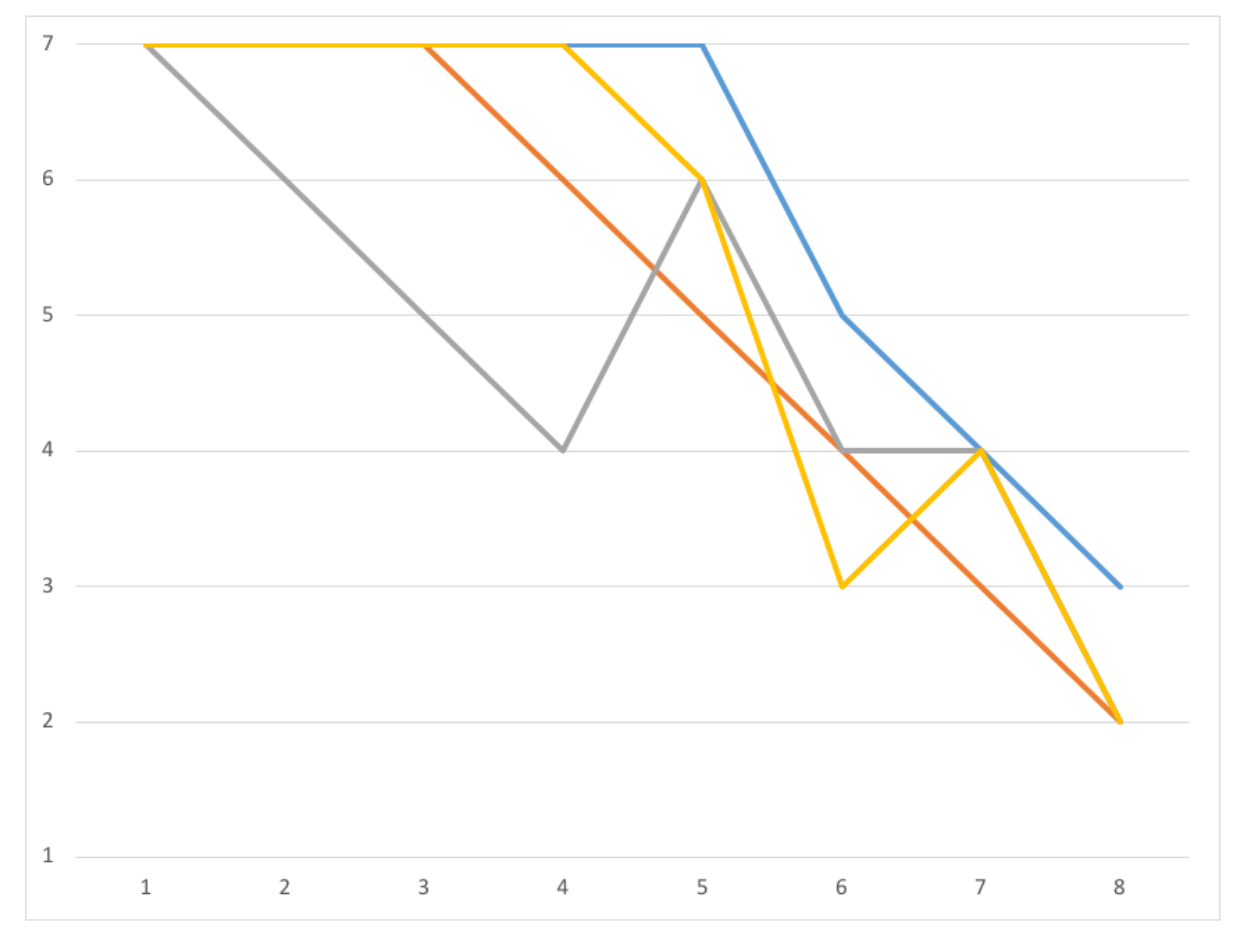

Figure 2: Mona, female student. Blue: satisfaction with the programme; orange: satisfaction with the lessons, grey: satisfactionwith the atmosphere; yellow: motivation to continue in the programme. 
Mona (figure 2) is 21 years old, has dropped out of several VET programmes, and is now studying a number of general subjects in order to enrol in a yet undefined VETprogramme. Very early in the interview, she says that it is very important for her that the school is situated far away from her home. Wanting a new start, she does not want to meet people she knows. However, asked about the oscillating and downwardly sloping graph, she explains that in the fourth week she got into trouble with another girl: "I just did not want to be at school with that girl. I was away for two weeks, because my grandmother died, and when I returned I was told that she (the classmate) never wants to talk to me again." When asked about why the orange graph (satisfaction with the lessons) declines in the fifth week from 7 to 5 , the explanation shows that she is involved in trouble among the girls in the class: "Someone from the class had told the supervisors that I and two other girls disrupt the lessons. I was called for an interview and I just thought it was so creepy and that I would never do a thing like that (inform against somebody) to the others (classmates)."

Furthermore, Mona is easily influenced by her academic performance, for example, when explaining why the yellow graph declined in the fourth week and rose again in the fifth week: "In the fourth week, I failed an assignment in the English class and in the fifth week, I had handed in a new version, so I was happy again."

Contrary to Mark, Mona does not take the initiative to talk with a teacher or a counsellor about her situation. She characterizes herself as a tough person who does not put up with anything and she mostly blames her surroundings for her social problems. Due to her toughness, her graph fluctuates a little; however, she gradually loses the motivation to attend school. Mona eventually drops out.

Students with a fluctuating decline are sensitive towards events and experiences both inside and outside school. These can be positive, but are mostly negative. A 22-year-old female student, Lila (figure 3), has previously dropped out of several programmes and is now training for a qualification as a retail assistant. Lila suffers from psychological problems and in the third week, when the yellow graph declines, Lila explains that she felt depressed: she could not get out of bed, she had problems falling asleep at night, and she began to doubt whether she would be able to complete the programme. She asked her doctor to adjust her medication, falling ill and staying at home for a few days.

Lila is influenced by the atmosphere in the class; the grey graph drops from 5 to 3 in the third week. She explains: "We don't speak to each other nicely in our class; classmates are rude to each other." She is also influenced by the lessons: in the third week, the orange graph declines from 7 to 5 and follows the blue graph in the fifth week, with the rating falling to 4. Lila explains: "We had too much teaching at the blackboard. A lot of us learn much better, when we have the things in our hands. One of my classmates and I were allowed to work outside the classroom and that helped me; I was back on track". 


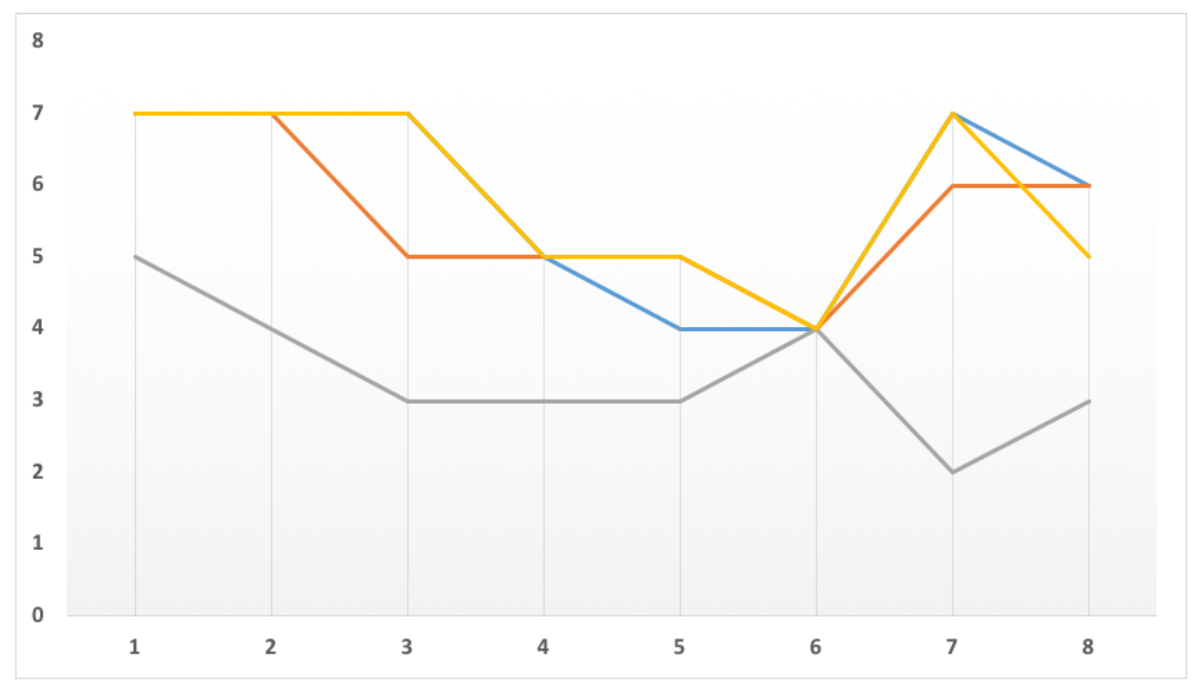

Figure 3: Lila, female student. Blue: satisfaction with the programme; orange: satisfaction with the lessons, grey: satisfaction with the atmosphere; yellow: motivation to continue in the programme.

Thus, Lila's oscillating graphs reflect a sensitivity to things like changes in teaching methods, meaning that the overall downward trend nonetheless shows fluctuations: having dropped from 7 to 4 during the first six weeks, the yellow graph climbs to 7 again in the seventh week before dropping to 5 in the eighth week. In Lila's case, psychological problems combine with her dissatisfaction and frustration regarding the classroom atmosphere and the lessons. She withdraws when she needs to consider her situation; she does not ask for help; she may listen to others' opinions, but she mostly listens to her gut feelings. At the time of writing the article, Lila has not dropped out of the programme.

Finally, a sudden decline means that the student's engagement appears stable for a period before suddenly declining significantly. Even though the students in this category perform quite well academically, they are unsure of themselves and have low self-efficacy, which may be due to a mental disorder. Like the other students with negative graphs, they do not take initiatives that might support them in continuing in their current programme.

Katja (figure 4) is an 18-year-old girl who is training for a qualification as a painter and decorator. She lives in accommodation provided by the school and is performing well at school, the teachers having no doubt that she will be able to pass her exams. She has previously dropped out of another VET programme at the same school, where she neither had problems of attainment. She also thrives socially and feels at ease in the class. As the yellow graph (motivation to continue in the programme) shows, she is initially confident that she will continue; however, the graph already falls abruptly to 4 in the second week, rising gradually during the following weeks before suddenly falling to 1 in the eighth week. Asked about this abrupt drop, she says that she suddenly decided to drop out; however, she finds it difficult to explain why: "I thought about it a lot; 
but I did not have the motivation to go to school. Furthermore, I was sure that I would not be able to pass the exams. Rather stop than fail the exam". She wants to avoid a defeat, to play it safe and be the one who withdraws before she is told to do so.

Katja also argues for her decision by blaming the type of tasks that she would have to perform as a painter and decorator: "Sandpapering, standing on a ladder in windy weather; it's just not me. I want to work with wallpaper, colours, and patterns". She had the same kind of reasons for dropping out of the previous VET programme. Her explanations for dropping out during the interview do not entirely seem to fit the reality. She is good at schoolwork and according to her teachers, she would be able to complete the programme. Still, it seems as if she is easily out of the saddle, convincing herself that the right decision is to drop out. Her personal history may shed light on her thoughts, feelings and actions. She has suffered from parental neglect, as both her parents are drug addicts. She has difficulties making commitments, fearing that she will be let down. Furthermore, her problems with getting up in the morning, partly due to various physical and psychological conditions, result in a high rate of absenteeism. She tells that she takes anti-depressants and sleeps a lot. Katja drops out of the programme convinced that this is a wise decision. At the time of dropping out, she already knows which VET programme she wants to enrol in instead.

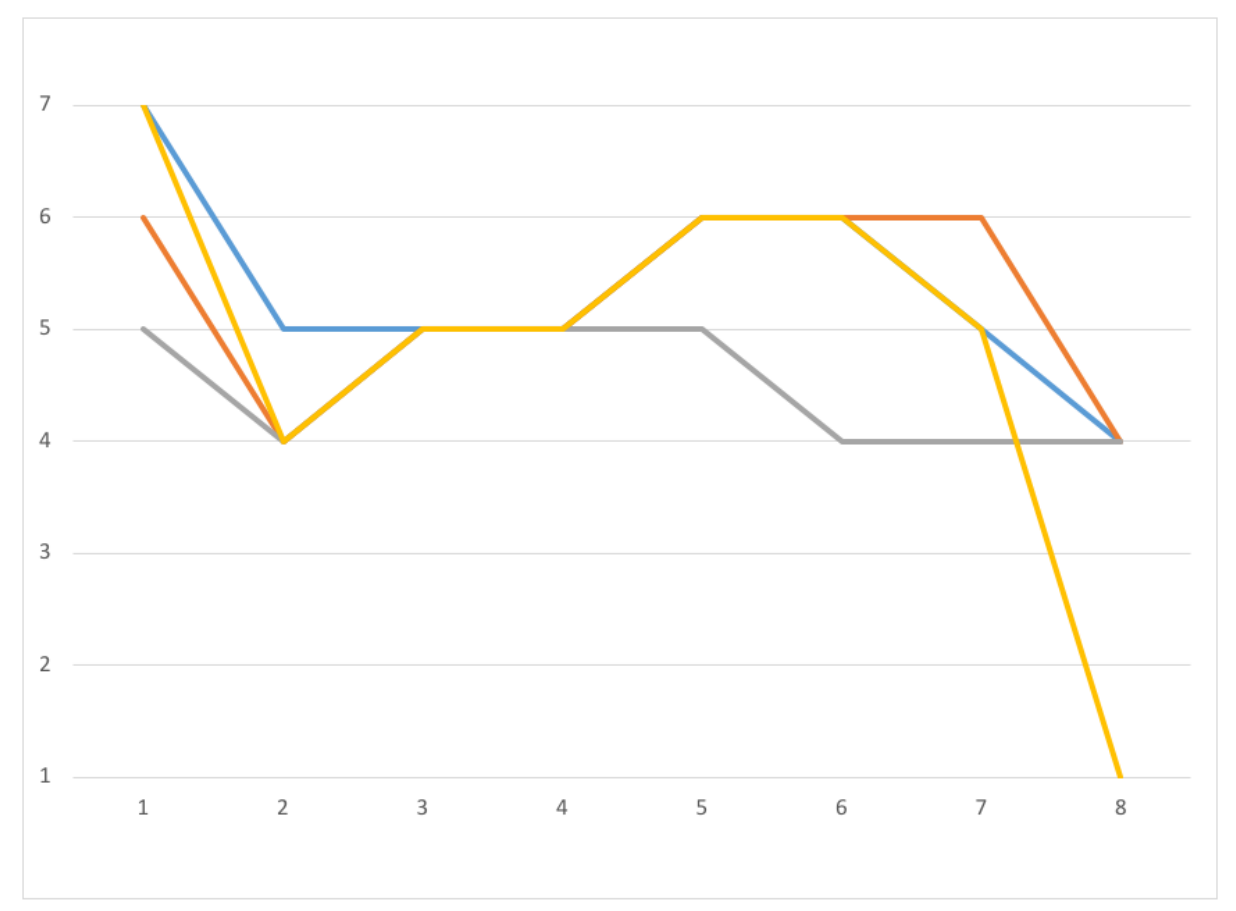

Figure 4: Katja, female student, Blue: satisfaction with the programme; orange: satisfaction with the lessons, grey: satisfaction with the atmosphere; yellow: motivation to continue in the programme. 
In relation to research questions 3 and 4 above, the four examples presented here exemplify different types of development and decision making processes. The central distinction between the unstable development' and the three types of negative developments is that students with an unstable development', despite feeling that they cannot cope with the academic challenges or the classroom environment, believe that they must continue their studies. They feel at ease socially, which helps them maintain a positive view of the programme, despite the challenges.

Students with one of the three types of negative developments provide explanations for changes that are largely similar to the students with an unstable development': they have experienced a setback academically or feel socially uncomfortable at the school. However, the students with a negative development' are more vulnerable, with their problems at school often combining with various psychological and social problems. Consequently, the events at school have a negative impact on the students' motivation to continue in the current programme. Furthermore, the students with a negative development' are disinclined to seek help.

\section{Discussion}

The study supports the findings of previous research: students' thoughts and actions when deciding whether to stay in or drop out of their current educational programme can be described as a fragmented disengagement process, characterized by paradoxes and a multiplicity of factors (Ferguson et al., 2005). Dropout must be analysed as a long-term process of disengagement, not as a binary incident or monumental decision (Alexander et al., 1997; Rumberger \& Rotermund, 2012). The decision to leave school should be understood as a reaction to a prolonged period of academic alienation (Fine, 1991; Fine \& Rosenberg, 1983; Brown \& Rodriquez, 2009).

However, by combining a survey over a period of 15 -week with in depth interviews the data collection metods in "To stay on track. New perspectives and sustainable solutions to dropout among young adults" enable an illustration of the contents and fluctuations of the decision-making processes. This includes the individual student's considerations and perceptions of his or her current situation in- and outside school providing knowledge about the interrelation of the various factors included in the decision-making processes. Thus, the data collection method not only provides information about events that influence the students' decisions but also about the decision-making processes.

The findings show that the decision-making processes in relation to staying in or dropping out of an educational programme differ considerably among students. Some cases show a stable development', in which things are gradually brought to a head. Other cases show turbulent developments, with students oscillating between wanting to drop out and wanting to continue. Finally, some developments are abrupt, with what appears a relatively stable development' suddenly leading to a decision to drop out. In relation to vocational education and training, the results call for a genuine interest in the individual student's thoughts, feelings and coping strategies.

The findings show that the students are sensitive to occurrences at school, even those 
that might be perceived as trivial. As Mark says, for example: "We have maths on Monday and I answered the survey on a Monday, so I was just in a bad mood." However, students differ in their ability to overcome such trivial matters, meaning that for some students (those with a negative development'), such matters are not trivial at all; they instead become the straw that breaks the camel's back at least in the students' narratives. In terms of discussing how to prevent dropout in VET, it is important to be aware that although students with a negative development' provide largely the same (official) explanations for changes as students with an unstable development', the changes have more severe consequences for students with a negative development'.

Comparing the findings to Harren's typology of three styles of decision-making process - the more rational', the more intuitive', and the more dependent' (Harren, 1979) it can be argued that many of the students' deliberations seem to be more intuitive than rational. Furthermore, many students in VET will have difficulties in explicating their thoughts and feelings, making it difficult to pinpoint crucial times in the students' decision-making processes. Further studies should include testing methods to elicit the students' feelings in relation to staying in or dropping out of education.

Finally, the study points to the importance of seeking help to find a constructive solution to one's problems. Some students will take the initiative to seek help; in other cases, the teacher or guidance counsellor will have to take the initiative to turn to the student. In order to do so the teachers and guidance counsellor have to be sensitive towards non-verbal indications of change in well-being among the students.

Two limitations should be mentioned in relation to the validity of the study's empirical data. The first concerns whether the fluctuations in the scores actually reflect the students' feelings and thoughts. As mentioned above, many of the occurrences mentioned seem (to the researchers) to be trivial matters, and the students might be exaggerating when answering the survey. However, the interviews serve to validate the scores in the survey in the sense that the students confirm that their thoughts and feelings corresponded to their scores. In addition none of the participants in the survey gives the exact same score throughout the surveys. This can be regarded as a test of validity in the sense that it suggests that, every week, the individual student consciously makes up his/ her mind about how to answer to each of the four questions.

The second limitation is that the study only covers a limited period; furthermore, a period during which the students are still enrolled in their chosen programme. This poses the question: does the study actually deal with dropouts? On the other hand, it can be argued that it is important in relation to preventing dropout that the students' scores reflect their experiences at the time when they occurred rather than their rationalizations after completing the programme or dropping out. As such, it can be argued that the students' answers provide a more authentic picture of their experiences than would be provided by them reminiscing about their time at school. Furthermore, the study highlights the importance of detecting and addressing students' problems at an early stage.

In relation to the issue of dropout in VET, the study points to the complexity of the students' decision-making processes including their thoughts, feelings, and actions, which can guide action in relation to preventing drop out. However, further research 
should aim at developing methods for eliciting the students' thoughts and feelings and their styles of decision-making processes.

\section{Conclusion}

Based on 31 students' weekly responses to the question of their motivation to continue their studies, supplemented by three questions concerning their perception of the programme, the lessons, and the atmosphere at the school, we have conducted interviews exploring these students' thoughts and actions in relation to events that have influenced their responses.

In line with previous research, the students' deliberations regarding whether to drop out or stay in their current programme can be described as a process influenced by a number of issues related to the school, current educational programme and to the students' lives outside school.

The results show that the students' responses follow different developments, some even and stable others sharp and abrupt, and yet others oscillating and turbulent. Knowledge about these developmental tendencies has practical benefits for preventing dropout in VET, enabling teachers, counsellors, or others involved in the students' educational progress to intervene at crucial moments during their education.

However, the results point to a need for more knowledge about the effects of the students' emotional processes in relation to their decisions as to whether or not to drop out, including developing methods to capture these processes.

\section{References}

Archambault, I., Janosz, M., Fallu, J.-S., \& Pagini, L.S. (2009). Student engagement and its relationship with early high school dropout, Journal of Adolescence, 32 (3), 651-670. Alexander, K. L., Entwisle, D. R., \& Horsey, C. S. (1997). From first grade forward: Early foundations of high school dropout. Sociology of Education, $70(2), 87-107$.

Blustein, D.L. (1987). Decision making styles and vocational maturity: An alternative perspective. Journal of Vocational Behavior, 30, 61-71.

Brown, T., \& Rodriquez, L.F. (2009). School and the Co-Construction of Dropout, International Journal of Qualitative Studies in Education, 22 (2), 221-242.

Cedefop (2016). Leaving education early: putting vocational education and training centre stage. Volume I: investigating causes and extent. Luxembourg: Publications Office. Cedefop research paper; No 57. doi:http://dx.doi.org/10.2801/893397

Cournoyer, L., Deschenaux, F. (2017). Decision-Making Rationales among Quebec VET Student Aged 25 and Older. International Journal For Research In Vocational Education And Training, 4(3), 226-248. doi:10.13152/IJRVET.4.3.3

Ekspertgruppen (2017). Bedre veje til en ungdomsuddannelse - opssumering af anbefalingsområder til regeringen. (English: Improved routes to youth education - areas of recommendations to the government. Ekspertgruppen om bedre veje tile n ung- 
domsuddannelse.

Ferguson, B., Tilleczek, K., Boydell, K., Rummens, J.A., Cote, D., \& Roth-Edney, D. (2005). Early school leavers: Understanding the lived reality of student disengagement from secondary school, Ministry of Education, Toronto, Canada.

Fine, M. (1991). Framing dropouts: Notes on the politics of an urban public high school. Albany: State University of New York Press.

Fine, M., \& Rosenberg, P. (1983). Dropping out of high school: The ideology of school and work. Journal of Education 165 (3), 257-272.

Finn, J. D. (1989). Withdrawing from school, Review of Educational Research, 59 (2), $117-142$.

Gati, I., Landman, S., Davidovitch, S., Asulin-Peretz, L., \& Gedassi, R. (2010). From career decision-making styles to career decision-making profiles: A multidimensional approach, Journal of Vocational Behavior, 76, 277-291.

Harren, V.A. (1979). A Model of Career Decision Making for College Students, Journal of Vocational Behavior, 14, 119-113.

Hodgson, D. (2007). Towards a more telling way of understanding early school leaving, Issues in Eduational Research, 17 (1), 40-61.

Hunt, R.G., Krzystofiak, F.J., Meindl, J.R., \& Yousry, A.M. (1989). Cognitive Style and Decision Making, Organizational Behavior and Human Decision Processes, 44, 436-453.

Jimerson, S., Egeland, B., Sroufe, L. A., \& Carlson, B. (2000). A prospective longitudinal study of high school dropouts examining multiple predictors across development. Journal of School Psychology, 38(6), 525-549.

Jørgensen, C.H. (ed.) (2011). Frafald $i$ erhvervsuddannelserne (English: dropout in VET). Roskilde Universitetsforlag.

Lamb, S. (2011). School Dropout and Inequality, In: Lamb, S., Markussen, E., Teese, R., Sandberg, N., \& Polesel, J. (eds.) (2011): School Dropout and Completion. International Comparative Studies in Theory and Policy. Dordrecht, Heidelberg, London, New York, Springer.

Lee, V.E., \& Burkham, D.T. (2003). Dropping out of High School: The Role of the School Organization and Structure, American Educational Research Journal, 40 (2), 353-393.

Lessard, A., Butler-Kisber, L., Fortin, L., Marcotte, D., Potvin, P., \& Royer, É. (2008). Shades of disengagement: High school dropouts speak out. Social Psychology of Education, 11 (1), 25-42.

Mau, W.-C. (2000). Cultural Differences in Career Decision-Making Styles and SelfEfficacy, Journal of Vocational Behavior, 57, 365-378.

Phillips, S.D., \& Pazienza, N.J. (1988). History and theory of the assessment of career development and decision making, In: Walsh, W.B. \& Osipow, S.H. (Eds.): Career decision making, Hillsdale, New Jersey: Erlbaum, 1-31.

Phillips, S.D., Pazienza, N.J., \& Ferrin, H. (1984). Decision making style and problemsolving appraisal. Journal of Counselling Psychology, 31, 497-502.

Rumberger, R.W. (2004). What can be done to reduce the dropout rate. In: Orfield, G. (ed.) (2004): Dropouts in America: Confronting the Graduation Rate Crisis, 
Cambridge MA: Harvard Education Press, 243-254.

Rumberger, R.W., \& Rotermund, S. (2012). The Relationship Between Engagement and High School Dropout, In: Christenson, S.L., Reschly, A.L. \& Wylie, C. (eds.) (2012): Handbook of Research on Student Engagement. Boston, Springer.

\section{Biographical Notes}

Dr Vibe Aarkrog PhD is associate professor in VET pedagogy at the Department of Education, Aarhus University, Denmark. Her research focuses on the interrelation between the school-based and workplace-based parts of dual programs and on transfer of training from school to workplace and vice versa.

Bjarne Wahlgren is professor at the Department of Education at Aarhus University, Denmark, and director for The National Centre of Competence Development. His research focuses on transfer of training, assessment of competences, dropout and teacher training in adult and vocational education.

Christian Hougaard Larsen is research assistant at the Department of Education, Aarhus University, Denmark. His research focuses on decision-making processes that leads to dropout or retention among young adults aged 18-25 years and aims to contribute to implementation and anchoring of sustainable strategies and methods for retention.

Dr Kristina Mariager-Anderson is associate professor in guidance at the Department of Education, Aarhus University. Her particular research interest is the cross field between adult education and career guidance, focusing on areas like vocational training and career guidance for low skilled adults in order to enable career transitions and labour market mobility; and on guidance in relation to drop out from adult education institution.

Susanne Gottlieb is research assistant at the Department of Education, Aarhus University, Denmark. As former head of department and associate professor at University College Copenhagen she has practical experience from vocational pedagogical development projects focusing on improvement of the interrelation between school-based and work-placed parts of duel programs. 